\title{
Dural-Based Cavernous Hemangioma Mimicking Convexity Meningioma-Case Report
}

\author{
Anuj Bhide ${ }^{1}$ Vernon Velho ${ }^{1}$ Maruti Pujari ${ }^{1} \quad$ Nimesh Jain
}

Address for correspondence Anuj Bhide, MCh, Department of Neurosurgery, J.J. Hospital and Grant Government Medical College, 4th Floor, Main Building, J.J. Hospital Campus, Byculla, Mumbai 400008, Maharashtra, India (e-mail: anujbhide@yahoo.in).

Cavernous hemangiomas and cavernomas are vascular tumors with nearly similar pathophysiologies, and they have been labeled interchangeably in the past but have a few subtle differences. ${ }^{1}$ They are benign tumors, most commonly intraparenchymal. Extra-axial cavernous hemangiomas account for only 0.4 to $2 \%$ of all intracranial vascular malformations. ${ }^{2}$ Extra-axial cavernous hemangiomas most commonly arise in the middle cranial fossa in or near the cavernous sinus. ${ }^{3}$ Other locations such as the convexity, posterior fossa, and anterior cranial fossa are very rare. ${ }^{4}$ Only 15 cases of convexity-based dural cavernous hemangiomas have been reported till date ( $\mathbf{- T a b l e ~} \mathbf{1}$ ). The most common differential diagnosis of a well-defined, dural-based tumor is a convexity meningioma. We hereby report a case of large dural-based frontal convexity cavernous hemangioma mimicking a convexity meningioma.

A 22-year-old woman presented with complaints of five episodes of seizures since 4 months and headache since 3 months. The seizures were partial in onset involving left side of the body with secondary generalization. At admission, the patient was conscious, oriented, and obeying commands with a Glasgow coma scale of 15 points. There were no neurodeficits. Computed tomography (CT) scan was performed, which showed a contrast-enhancing, dural-based, homogenous, well-circumscribed lesion having a maximum diameter of $5.5 \mathrm{~cm}$ in the right frontal convexity (-Fig. 1). On magnetic resonance imaging (MRI), the lesion was found to be isointense on $\mathrm{T} 1$ and homogenously hyperintense on $\mathrm{T} 2$ with brilliant postcontrast enhancement. However, there was no obvious dural tail sign, and the central core of the lesion showed increased T2 intensity than the periphery of the tumor (-Fig. 1). There was also perilesional edema with significant mass effect. On imaging studies, a provisional diagnosis of a frontal convexity meningioma was made. The patient was planned for right frontal craniotomy and Simpson's grade 1 resection of the lesion. Intraoperatively it was observed that the tumor was adherent to the convexity dura mater. The tumor was extremely vascular, reddish brown, with adequate plane between the tumor and the surrounding edematous parenchyma with small arterial feeders and

received

April 6, 2018

accepted

May 28, 2018

published online

November 27, 2018 areas of adhesions. The tumor was excised en bloc, and tumor resection was confirmed on postoperative CT scan (-Fig. 2). Unlike a convexity meningioma, the tumor did not lose its vascularity even after disconnecting the involved dural island from the surrounding dura mater. On histopathologic analysis, the tumor showed varying sized blood vessels with intraluminal red cells on an acellular hyalinized stromal background ( - Fig. 3). On immunohistochemistry, the tumor cells were CD34-positive suggesting an endothelial origin. There were occasional foci of dystrophic calcification. The diagnosis of a cavernous hemangioma was confirmed. The patient had an uneventful postoperative course and is seizure free for the past 2 years. Follow-up imaging has shown no residual lesion or recurrence.

Cavernous malformations belong to a spectrum of vascular malformations wherein the vasculature forms cisterns or caverns without a proper medial and adventitial wall to these cisterns leading to chances of recurrent hemorrhages within these malformations. They account for 10 to $15 \%$ of all central nervous system vascular anomalies. ${ }^{1}$ Two separate entities have been included in the spectrum of cavernous malformations: cavernomas and cavernous hemangiomas. Cavernomas tend to be familial, multiple, with perilesional hemosiderin rings and higher hemorrhagic propensity as compared with cavernous hemangiomas. Therefore, cavernomas present most commonly with sequelae of bleeding like seizures and focal neurologic deficits, whereas cavernous hemangiomas can go unnoticed until they reach large sizes and cause mass effect. ${ }^{1}$ The most common location for cavernomas is supratentorial and intraparenchymal. ${ }^{1}$ The pathologic hallmarks of cavernomas are the presence of sinusoids with a single layer of endothelium and thin collagenous wall with lack of smooth muscle fibers and elastic fibers. There are classic leaky sinusoids with hemosiderin staining and gliotic reaction in the adjacent brain. ${ }^{5}$ Cavernous hemangiomas, on the other hand, most commonly occur in the middle cranial fossa and sellar region, in close relation with the cavernous sinus. Cavernous hemangiomas of the cavernous sinus have been classified histopathologically into two subgroups based on operative findings: type A, having

(C)2018 Neurological Surgeons'

License terms

Society of India

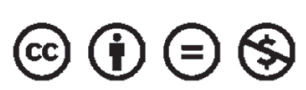

10.1055/s-0038-1672355. ISSN 2277-954X. 
Table 1 Literature review of reported cases of dural-based convexity cavernous hemangiomas

\begin{tabular}{|c|c|c|c|c|c|c|c|c|}
\hline Authors & Year & Site & Age $(y) / \operatorname{Sex}$ & Seizures & Hemorrhage & Headache & $\begin{array}{l}\text { Neurologic } \\
\text { deficits }\end{array}$ & Treatment \\
\hline Ito et al & 1978 & $\begin{array}{l}\text { Parietal } \\
\text { convexity }\end{array}$ & NR & NR & NR & NR & NR & NR \\
\hline Kunishio et al & 1986 & NR & $61 / \mathrm{F}$ & No & No & No & Yes & Surgery \\
\hline Perry et al & 1993 & $\begin{array}{l}\text { Parietal } \\
\text { convexity }\end{array}$ & $77 / F$ & Yes & No & No & No & Surgery \\
\hline Revuelta et al & 1994 & $\begin{array}{l}\text { Occipital } \\
\text { convexity }\end{array}$ & $66 / M$ & No & No & Yes & No & Surgery \\
\hline Lewis et al & 1994 & $\begin{array}{l}\text { Parietal } \\
\text { convexity }\end{array}$ & $36 / F$ & No & No & Yes & Yes & Surgery \\
\hline Suzuki et al & 1996 & $\begin{array}{l}\text { Frontal } \\
\text { convexity }\end{array}$ & $78 / \mathrm{F}$ & No & Yes & No & Yes & Surgery \\
\hline Hyodo et al & 2000 & $\begin{array}{l}\text { Parieto-oc- } \\
\text { cipital } \\
\text { convexity }\end{array}$ & $77 / \mathrm{M}$ & No & No & No & Yes & Surgery \\
\hline Shen et al & 2000 & $\begin{array}{l}\text { Parietal } \\
\text { convexity }\end{array}$ & $18 / \mathrm{F}$ & No & No & Yes & Yes & Surgery \\
\hline $\begin{array}{l}\text { McKechnie } \\
\text { et al }\end{array}$ & 1998 & $\begin{array}{l}\text { Occipital } \\
\text { convexity }\end{array}$ & $47 / F$ & No & No & NO & Yes & Surgery \\
\hline Hwang et al & 2009 & $\begin{array}{l}\text { Frontal } \\
\text { convexity }\end{array}$ & $61 / M$ & No & Yes & Yes & Yes & Surgery \\
\hline Joshi et al & 2009 & $\begin{array}{l}\text { Parieto-oc- } \\
\text { cipital } \\
\text { convexity }\end{array}$ & $15 / M$ & No & No & Yes & No & Surgery \\
\hline $\begin{array}{l}\text { Sakakibara } \\
\text { et al }\end{array}$ & 2010 & $\begin{array}{l}\text { Fronto- } \\
\text { parietal } \\
\text { convexity }\end{array}$ & $59 / \mathrm{M}$ & No & No & No & Yes & Surgery \\
\hline Yonezawa et al & 2014 & NR & $78 / \mathrm{F}$ & No & No & Yes & No & Surgery \\
\hline $\begin{array}{l}\text { Di Vitantonio H } \\
\text { et al }\end{array}$ & 2015 & $\begin{array}{l}\text { Frontal } \\
\text { convexity }\end{array}$ & $30 / \mathrm{F}$ & No & No & Yes & No & Surgery \\
\hline Pelluru et al & 2018 & $\begin{array}{l}\text { Tempo- } \\
\text { roparietal } \\
\text { convexity }\end{array}$ & $26 / M$ & Yes & No & No & No & Surgery \\
\hline
\end{tabular}

Source: Modified with permission from Di Vitantonio et al. ${ }^{19}$

thin-walled vascular channels, associated with severe bleeding and type B, having well-formed vessels with solid parenchyma. The hemosiderin rings give cavernomas the classic "popcorn" or "berry" appearance due to loss of signal. The T1- and T2-weighted signals vary depending on the age of the hemorrhage. Gradient echo and susceptibility-weighted images can detect small, multiple cavernomas with higher sensitivity. ${ }^{6}$ In contrast, cavernous hemangiomas are hypointense on T1-weighted, uniformly hyperintense on T2-weighted imaging and show brilliant gadolinium contrast enhancement. The lack of hemosiderin-ring signal loss and the occasional presence of a dural tail with dural base can be misleading. After review of the literature, only 15 cases of dural-based convexity cavernous hemangiomas have been reported in literature. ${ }^{1-3,7-19}$ ( - Table 1). Cases of extracranial temporalis muscle cavernous hemangiomas have been reported before. ${ }^{20}$ Most cases reported were diagnosed as convexity meningiomas, due to their similar radiologic features. In the reported cases, there was only slightly higher female prevalence (8:7). Eight patients were older than 60 years, whereas only two cases were reported younger than 20 years of age. Only two cases reported seizures as the presenting features, and only two cases had hemorrhage as an imaging finding. All reported patients have undergone surgery.

All current evidence indicates that treatment of choice for these lesions is total surgical removal. However, like any other vascular malformation, stereotactic radiosurgery represents a therapeutic option. Cavernous hemangiomas in the middle fossa can be challenging because of their location and high vascular supply, and hence preoperative radiation and embolization are recommended to reduce operative complications. ${ }^{7,12}$ However, because the working diagnosis of a convexity meningioma is mostly made before operating these tumors, surgery has been performed without any preoperative intervention in most cases. Simpson's grade 1 removal with resection of the involved dura is recommended for these tumors. On suspicion that the tumor may not actually be a meningioma during surgery, it is imperative that the tumor be excised as whole, because the risk of bleeding is much higher than in a meningioma. The tumor capsule should be 


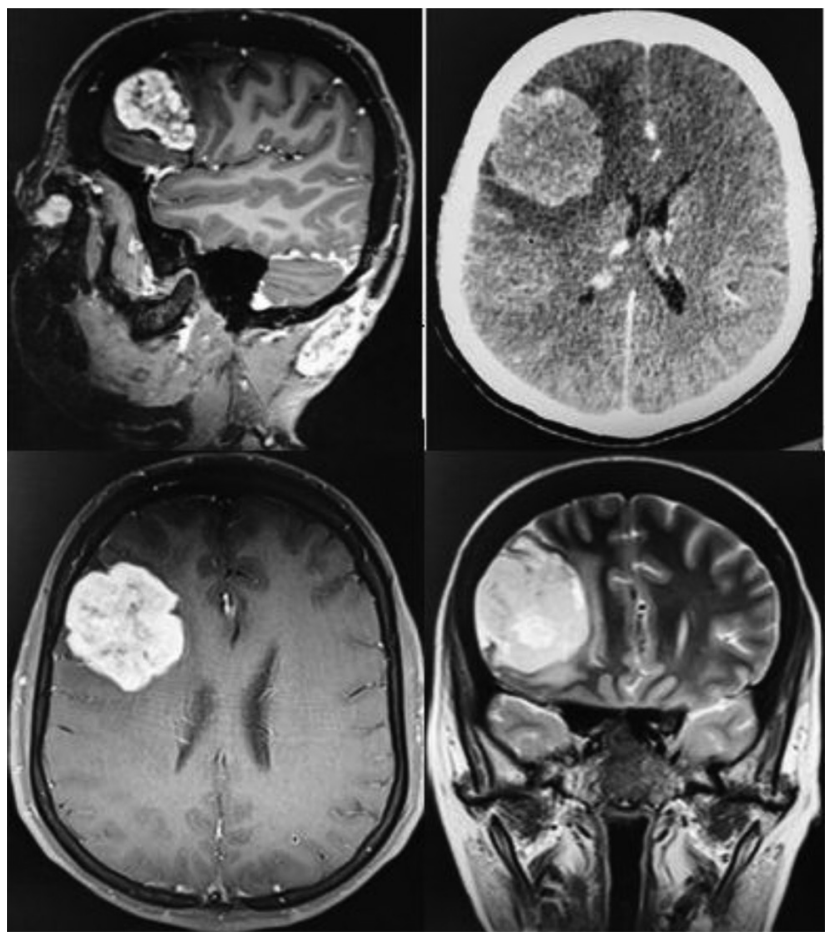

Fig. 1 Preoperative radiological imaging (CT and MRI) showing a well-circumscribed, contrast-enhancing, dural-based lesion in the right frontal region.

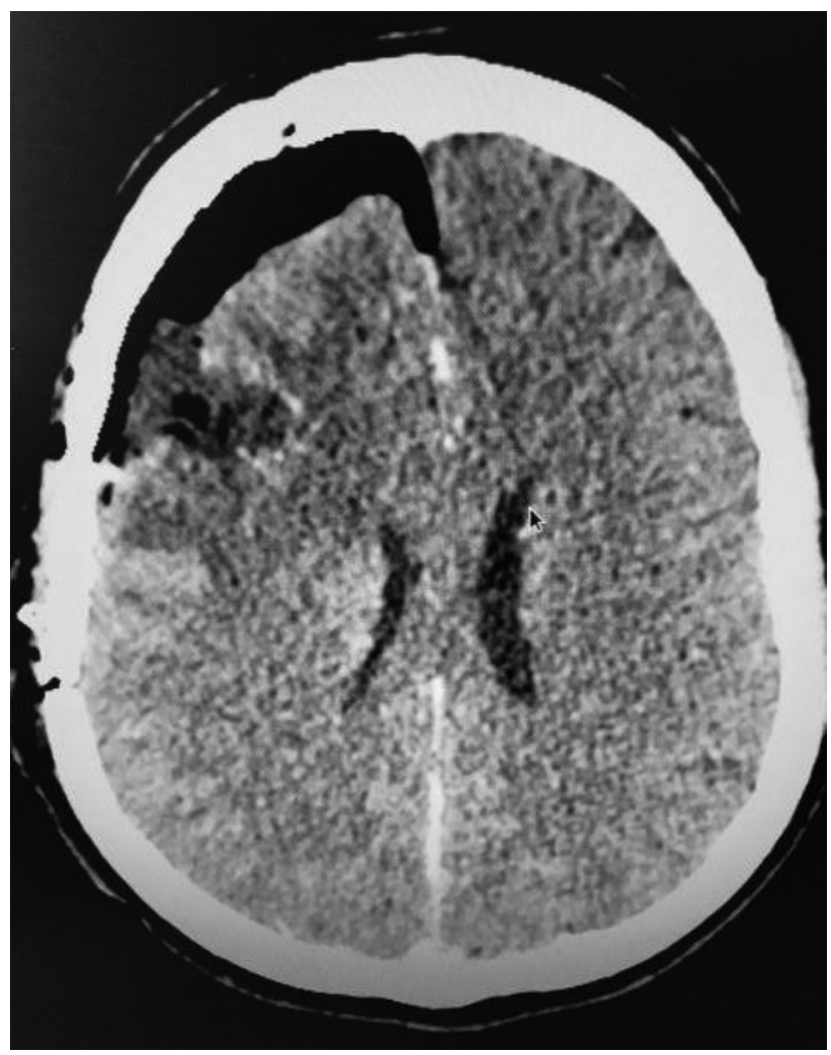

Fig. 2 Postoperative CT scan axial image showing complete excision of the lesion.

left intact. Careful coagulation of the exposed part of the tumor can help shrink the tumor and separate it from the

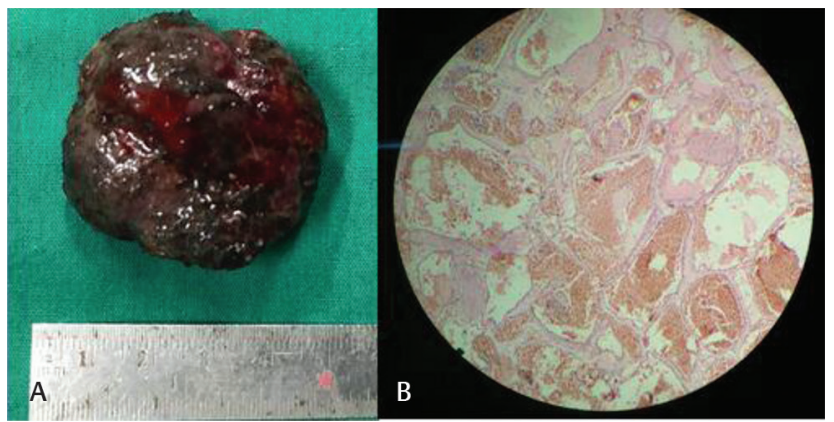

Fig. 3 Pathology specimen (A) and the postoperative hematoxylin and eosin stain slides (B) of the cavernous hemangioma.

adjoining parenchyma. In cases in which complete removal is not possible, it is advisable to treat the lesion with radio surgery after histopathologic confirmation., ${ }^{2,2}$ Complete resection of the tumor is possible with minimal blood loss and appears to be curative. ${ }^{10} \mathrm{~A}$ possibility of a cavernous hemangioma should be kept in mind when a radiologic diagnosis of a convexity meningioma is made. Unlike cavernomas that have a propensity of recurrent hemorrhage, cavernous hemangiomas are clinically silent until they attain a large size and usually present with mass effect. Complete resection of these lesions is the treatment of choice. Breach in the tumor capsule should be avoided during surgery, as these tumors are highly vascular.

\section{Conflicts of Interest}

There are no conflicts of interest.

\section{Funding}

None.

\section{References}

1 Pelluru PK, Rajesh A, Uppin MS. Dural-based giant cavernous hemangioma mimicking a meningioma: lessons learnt. Neurol India 2017;65(5):1173-1176

2 Melone AG, Delfinis CP, Passacantilli E, Lenzi J, Santoro A. Intracranial extra-axial cavernous angioma of the cerebellar falx. World Neurosurg 2010;74(4-5):501-504

3 Shen WC, Chenn CA, Hsue CT, Lin TY. Dural cavernous angioma mimicking a meningioma and causing facial pain. J Neuroimaging 2000;10(3):183-185

4 Gutiérrez-González R, Casanova-Peño I, Porta-Etessam J, Martínez A, Boto GR. Dural cavernous haemangioma of the anterior cranial fossa. J Clin Neurosci 2010;17(7):936-938

5 McCormick WF. The pathology of vascular ("arteriovenous") malformations. J Neurosurg 1966;24(4):807-816

6 Zhu WZ, Qi JP, Zhan CJ, et al. Magnetic resonance susceptibility weighted imaging in detecting intracranial calcification and hemorrhage. Chin Med J (Engl) 2008;121(20):2021-2025

7 Hwang SW, Pfannl RM, Wu JK. Convexity dural cavernous malformation with intradural and extradural extension mimicking a meningioma: a case report. Acta Neurochir (Wien) 2009;151(1):79-83

8 Hyodo A, Yanaka K, Higuchi O, Tomono Y, Nose T. Giant interdural cavernous hemangioma at the convexity. Case illustration. J Neurosurg 2000;92(3):503

9 Ito J, Konno K, Sato I, Kameyama S, Takeda S. [Convexity cavernous hemangioma, its angiographic and CT findings. No To Shinkei 1978;30(7):737-747 
10 Joshi V, Muzumdar D, Dange N, Goel A. Supratentorial convexity dural-based cavernous hemangioma mimicking a meningioma in a child. Pediatr Neurosurg 2009;45(2):141-145

11 Kunishio K, Sunami N, Yamamoto Y, Satoh T, Asari S, Ohtsuki Y. [A case of convexity cavernous hemangioma associated with meningioma] [in Japanese]. No Shinkei Geka 1986;14(12):1487-1491

12 Lewis AI, Tew JM Jr, Payner TD, Yeh HS. Dural cavernous angiomas outside the middle cranial fossa: a report of two cases. Neurosurgery 1994;35(3):498-504, discussion 504

13 McKechnie S, Harper C, Besser M. Durally-based occipital cavernous haemangioma indistinguishable from meningioma. J Clin Neurosci 1998;5(1):105-108

14 Perry JR, Tucker WS, Chui M, Bilbao JM. Dural cavernous hemangioma: an under-recognized lesion mimicking meningioma. Can J Neurol Sci 1993;20(3):230-233

15 Revuelta R, Teixeira F, Rojas R, Juambelz P, Romero V, Valdes J. Cavernous hemangiomas of the dura mater at the convexity. Report of a case and therapeutical considerations. Neurosurg Rev 1994;17(4):309-311
16 Sakakibara Y, Matsumori T, Taguchi Y, Koizumi H. Supratentorial high convexity intradural extramedullary cavernous angioma: case report. Neurol Med Chir (Tokyo) 2010; 50(4):328-329

17 Suzuki K, Kamezaki T, Tsuboi K, Kobayashi E. Dural cavernous angioma causing acute subdural hemorrhage-case report. Neurol Med Chir (Tokyo) 1996;36(8):580-582

18 Yonezawa U, Ikawa F, Hamasaki O, Hidaka T, Kurokawa Y, Onuma $\mathrm{H}$. [A case of cavernous angioma at the convexity in the dura mater: characteristics of images in the literature] [in Japanese] No Shinkei Geka 2014;42(8):731-735

19 Di Vitantonio H, De Paulis D, Ricci A, Marzi S, Dehcordi SR, Galzio RJ. Cavernous hemangioma of the dura mater mimicking meningioma. Surg Neurol Int 2015; 6(Suppl 13):S375-S378

20 Turel MK, Kiehl TR, Gentili F. Extracranial temporal cavernous hemangioma: differential diagnosis, and a review of literature. Neurol India 2016;64(6):1347-1351 